\section{Occurrence and molecular characteristics of Listeria monocytogenes isolated from ready-to-eat meats in Hanoi, Vietnam}

\author{
Thuy Phung, Tung Tran, Dung Pham, \\ Anh To, Hoa Le \\ School of Biotechnology and Food \\ Technology, Hanoi University of Science \\ and Technology, Hanoi, Vietnam
}

\begin{abstract}
Listeria monocytogenes represents one of the most serious threats to food safety. Several studies have shown that Ready-ToEat (RTE) meats are an important vehicle responsible for listeriosis in human. In Vietnam, little is known about the occurrence and molecular characteristics of L. monocytogenes in meat products, which are essential for developing monitoring plans and control measures. In the present study, we investigated the occurrence of $L$. monocytogenes in 258 sausage and sliced meat samples collected during the period of 2013-2015 and determined the genetic diversity of the isolates using multi-locus sequence typing (MLST). Overall, $L$. monocytogenes was present in 19/129 (14.7 $\%)$ and 40/129 (31.0\%) sausage and sliced meat samples respectively, with the peak of occurrence being in summer. Furthermore, a minimum spanning tree was constructed based on MLST data of 47 isolates. A total of 15 sequence types were found, with five being novel. Notably, the majority of the isolates (34/47) belonged to the hypervirulent clonal complexes 1,2 , and 3 .
\end{abstract}

\section{Introduction}

Listeria monocytogenes is a grampositive, facultative intracellular bacterium that causes listeriosis (Rogalla and Bomar, 2019). Ubiquitous in nature, $L$. monocytogenes may cross-contaminate food products during handling processes (Di Bonaventura et al., 2008; Tabit, 2018). Unlike other common food pathogens, $L$. monocytogenes can survive during cold storage and grow to significant numbers to cause listeriosis. Once the infection has occurred, especially

in immunocompromised individuals, pregnant women or the elderly, L. monocytogenes may cause severe and life-threatening complications such as bacteremia, meningitis, seizures, miscarriage or even death (Schlech, 2000).

Ready-To-Eat (RTE) foods, which are often refrigerated for extended periods and consumed without further treatment, are a relevant route of $L$. monocytogenes infection in human. Sliced meats and RTE sausages were among the most common food vehicles in recorded outbreaks and sporadic cases of food associated listeriosis from 1996 to 2018 (Desai et al., 2019). Recently, a L. monocytogenes outbreak in Spain and a multi-country outbreak in Netherlands and Belgium totaling 243 cases, six deaths and seven miscarriages, were linked to RTE meat products (ECDC-EFSA, 2019; WHO, 2019).

In Vietnam, previous studies have evidenced the presence of $L$. monocytogenes in raw and processed meats. Thuc et al. (2008) showed that $21.7 \%$ of sausage samples collected during the period of 20062007 were contaminated with $L$. monocytogenes; Ngo Chung Thuy et al. (2008) revealed that up to $34.3 \%$ of the refrigerated minced pork sold in Hanoi were positive for L. monocytogenes; Xuan Binh et al. (2017) reported a contamination rate of approximately $10 \%$ in beef, pork, and poultry samples collected between 2015 and 2016 in Northern Vietnam. Meanwhile, Vietnam has enforced a zero tolerance policy $(0 / 25 \mathrm{~g})$ regarding L. monocytogenes for RTE meats (Vietnam Ministry of Health's Decision No 46/2007/QD-BYT). However, the occurrence of $L$. monocytogenes in RTE meats in Vietnam has not been studied extensively, and the epidemiological characteristics of the L. monocytogenes isolates have not been assessed. Therefore, the aim of this study was to determine the occurrence of L. monocytogenes in RTE meat products collected in Hanoi during the period of 2013-2015 and characterize the isolated strains using Multi-locus Sequence Typing (MLST).

\section{Materials and Methods}

\section{Sample collection}

RTE sausage and sliced meat products were collected at retail stores and supermarkets in Hanoi during the period of 2013-2015, once per season per product. At each sampling, at least ten products per category (sausage and sliced meat) were collected, for a total of 129 sausage and 129 sliced meat samples. Samples were ensured to be less than 30 days old (from manufacture dates). Three packages of the same lot were pooled and minced using an A 11 basic Analytical mill (IKA); of which, 25 grams were used for isolation of $L$. monocytogenes.
Correspondence: Hoa Quang Le, School of Biotechnology and Food Technology, Hanoi University of Science and Technology, Hanoi, Vietnam.

Tel.: +84.832208986

E-mail: hoa.lequang@hust.edu.vn

Key words: Listeria monocytogenes, Readyto-eat meats, Epidemiology, Multi-locus sequence typing, Sausage, Sliced meat

Contributions: TP and TT contributed equally to the work. TP, AT, HL conceived and designed the study. TP, TT, DP, AT collected the data. TT, HL performed the analysis. TP, TT, HL drafted the manuscript. All authors read and approved the final manuscript.

Conflict of interest: The authors declare no conflict of interests.

Funding: This research was funded by project No. T2015-033 of Hanoi University of Science and Technology.

Acknowldegements: This research was supported by Project No. T2015-033 of Hanoi University of Science and Technology. We would like to thank Applied Maths for their support and permission to use the temporary BioNumerics evaluation license.

Received for publication: 18 December 2019. Revision received: 3 March 2020.

Accepted for publication: 5 March 2020

This work is licensed under a Creative Commons Attribution-NonCommercial 4.0 International License (CC BY-NC 4.0).

(C) Copyright: the Author(s), 2020

Licensee PAGEPress, Italy

Italian Journal of Food Safety 2020; 9:8772 doi:10.4081/ijfs.2020.8772

\section{Isolation of $\boldsymbol{L}$. monocytogenes}

Isolation of L. monocytogenes from food samples was carried out using RAPID'L.mono Medium (BIO-RAD) according to the manufacturer's specifications. Firstly, enrichment was performed by homogenizing 25 grams of samples in $225 \mathrm{~mL}$ of Half Fraser broth (BIO-RAD) using a Stomacher 400 Circulator (Seward, England) and incubated at $30{ }^{\circ} \mathrm{C}$ for 24 hours. Thereafter, enriched cultures were spread on RAPID'L.mono Medium (BIO-RAD) and incubated at $37^{\circ} \mathrm{C}$ for another 24 hours. Suspected $L$. monocytogenes colonies (blue without yellow halo) were then streaked onto RAPID'L.mono Medium before being purified twice by streaking onto Tryptone Soya Yeast Extract Agar (TSYEA). Colonies were confirmed by PCR using primers (F: 5'- CGGAGGTTCCGCAAAAGATG-3'; R: 5'- CCTCCAGAGTGATCGATGTT-3') 
targeting $h l y A$ gene of the bacterium (Furrer et al., 1991). Positive isolates were then grown in BHI Broth (Oxoid) and stored in $50 \%$ glycerol at $-80{ }^{\circ} \mathrm{C}$.

\section{DNA extraction}

DNA of L. monocytogenes was extracted using GeneJET Genomic DNA Purification Kit (ThermoFisher Scientific, USA) according to the manufacturer's instructions. Briefly, isolates were streaked from glycerol stocks onto TSYEA, confirmed by PCR as described above and grown overnight in $\mathrm{BHI}$ broth. Subsequently, cell pellets (from $5 \mathrm{~mL}$ of BHI culture) were homogenized in 180 $\mu \mathrm{L}$ of Gram-positive bacteria lysis buffer (20 mM Tris $\mathrm{HCl}, \mathrm{pH}$ 8,0; 2 mM EDTA; 1,2 \% Triton X-100; $20 \mathrm{mg} / \mathrm{ml}$ lysozyme) and incubated at $37^{\circ} \mathrm{C}$ for 30 minutes. To release DNA from the cells, $200 \mu \mathrm{L}$ of Lysis Solution and $20 \mu \mathrm{L}$ of Proteinase K were added, followed by incubation at $56{ }^{\circ} \mathrm{C}$ for 30 minutes. Subsequently, $20 \mu \mathrm{L}$ of RNase A solution was added and the mixture was incubated for 10 minutes at room temperature. After adding $400 \mu \mathrm{L}$ of $50 \%$ ethanol, the mixture was loaded onto the spin column and subjected to centrifugation at $6000 \times \mathrm{g}$ ( 1 minute). The flow-through was discarded and the column was washed with $500 \mu \mathrm{L}$ of Wash Buffer I and II respectively. After elution with $200 \mu \mathrm{L}$ of Elution Buffer, DNA concentration and quality were assessed by measuring absorbances at 260 $\mathrm{nm}, 280 \mathrm{~nm}$ and $230 \mathrm{~nm}$ on a Nanodrop 2000 (ThermoFisher Scientific, USA).

\section{Multi-locus sequencing typing and phylogenetic analysis}

Multi-locus sequencing typing of $47 \mathrm{~L}$. monocytogenes isolates was performed following the scheme available at https://bigsdb.pasteur.fr/listeria/primers_use d.html. Specifically, internal fragments of seven house-keeping genes $a b c Z$ (ABC transporter), bglA (beta glucosidase), cat (catalase), dapE (succinyl diaminopimelate desuccinylase), dat (D-amino acid aminotransferase), $\quad l d h \quad$ (L-lactate dehydrogenase), and $\operatorname{lhk} A$ (histidine kinase) were amplified and sequenced. PCR amplifications were carried out using published primers, and the following PCR program was used: $94^{\circ} \mathrm{C}$ (4 mins); 35 cycles of $94^{\circ} \mathrm{C}(30 \mathrm{~s}), 52^{\circ} \mathrm{C}(30 \mathrm{~s}), 72^{\circ} \mathrm{C}(2 \mathrm{mins})$; and $72^{\circ} \mathrm{C}$ (10 mins). PCR reactions were prepared in a final volume of $50 \mu \mathrm{L}$, containing $25 \mu \mathrm{L}$ of $\mathrm{GoTaq}^{\circledR} \mathrm{G} 2$ Hot Start Colorless Master Mix 2X (Promega, USA), $0.4 \mathrm{pmol} / \mu \mathrm{L}$ of each primer, and $10 \mathrm{ng}$ of DNA template. PCR products were purified using GeneJET PCR Purification (ThermoFisher Scientific) following manufacturer's instructions and verified on
$1.5 \%$ agarose gel before being sent to Macrogen (Seoul, Korea) for sequencing. All sequences have been submitted to GenBank under accession numbers MN460372MN460653.

Allele numbers of the obtained sequences were determined by querying against $L$. monocytogenes MLST database at https://bigsdb.pasteur.fr/listeria/listeria.html. Allelic profile of seven house-keeping genes were then used to define the sequence type (ST) and clonal complex (CC) of each isolate (Ragon et al., 2008). BioNumerics software (temporary evaluation license, Applied Maths, Belgium) was used to construct a minimum spanning tree (MST), showing phylogenetic relationships between isolates. Permission to publish these results was obtained from Applied Maths.

\section{Statistical analysis}

Occurrence of L. monocytogenes was calculated for individual food categories (sausage and sliced meat). Chi Square test was performed to compare the occurrence and compute P-values. Mann-Kendall test was used to test for consistently increasing or decreasing trends (monotonic) in occurrence of $L$. monocytogenes over time (Pohlert, 2015). All statistical analyses were done using Excel add-in X1Stat v2019.1.1 (Addinsoft, Boston, USA).

\section{Results}

\section{Occurrence and seasonality of L. monocytogenes in RTE foods}

Occurrence of L. monocytogenes in sausages and sliced meats ranged from 8.2 $\%$ to $20.0 \%$ and $26.8 \%$ to $35.4 \%$ between 2013 and 2015 respectively (Table 1). Combining data from all three years, contamination of L. monocytogenes was significantly more frequent in sliced meat than in sausage $(31.0 \%$ vs. $14.7 \%$, $\left.\chi^{2}=9.691, \mathrm{P}=0.002\right)$. Notably, there was a drop in the occurrence of L. monocytogenes in sausages in $2015(8.2 \%$ vs. $17.5 \%$ in 2013 and $20.0 \%$ in 2014); however, there was no significant upward or downward trend in L. monocytogenes rate over the years (Mann-Kendall test, $\mathrm{P}>0.05$ ). Similarly, no significant monotonic trend was found for $L$. monocytogenes rate in sliced meats. Regarding the occurrence of $L$. monocytogenes in both food types in relation to sampling season, significant differences were found $\left(\chi^{2}=12.083, \mathrm{P}=0.007\right)$, with the peak being in summer $(37.5 \%)$ and the lowest occurrence being in winter $(12.5 \%)$ (Table 2). Further studies are required to validate the correlation between environmental temperature and occurrence of L. monocytogenes in RTE foods in Vietnam.

Table 1. Occurrence of $L$. monocytogenes in RTE sausages and sliced meats collected between 2013 and 2015.

\begin{tabular}{|c|c|c|c|}
\hline Year & Sample type & Number of test sample & Positive samples (\%) \\
\hline 2013 & $\begin{array}{l}\text { Sausage } \\
\text { Sliced meat }\end{array}$ & $\begin{array}{l}40 \\
40\end{array}$ & $\begin{array}{c}7(17.5) \\
12(30.0)\end{array}$ \\
\hline 2014 & $\begin{array}{l}\text { Sausage } \\
\text { Sliced meat }\end{array}$ & $\begin{array}{l}40 \\
48 \\
\end{array}$ & $\begin{array}{c}8(20.0) \\
17(35.4)\end{array}$ \\
\hline 2015 & $\begin{array}{l}\text { Sausage } \\
\text { Sliced meat }\end{array}$ & $\begin{array}{l}49 \\
41\end{array}$ & $\begin{array}{c}4(8.2) \\
11(26.8)\end{array}$ \\
\hline Total & $\begin{array}{l}\text { Sausage } \\
\text { Sliced meat }\end{array}$ & $\begin{array}{l}129 \\
129\end{array}$ & $\begin{array}{l}19(14.7) \\
40(31.0)\end{array}$ \\
\hline
\end{tabular}

Table 2. Occurrence of $L$. monocytogenes in RTE sausages and sliced meats in relation to sampling season.

\begin{tabular}{lcc} 
Sampling season & Number of test sample & Positive samples (\%) \\
Spring & 64 & $14(21.9)$ \\
Summer & 64 & $24(37.5)$ \\
\hline Autumn & 66 & $13(19.7)$ \\
Winter & 64 & $8(12.5)$ \\
\hline Total & 258 & $59(22.9)$
\end{tabular}




\section{Multi-locus sequence typing of}

\section{L. monocytogenes isolates}

A minimum spanning tree was constructed based on MLST data to show the phylogenetic relatedness between $47 \mathrm{~L}$. monocytogenes isolates (12/59 isolates could not be recovered from glycerol stocks). These isolates were segregated into 15 sequence types (ST), with five of which being novel (assigned as ST1585, 1586, 1587, 1588, and 1589) (Figure 1). Irrespective of the food source, ST2 was the most prevalent (17/47), followed by ST3 $(12 / 47)$. On the other hand, the other STs comprised of only one or two sequences. All sequences could be attributed to existing clonal complexes (CC): $\mathrm{CC} 1, \mathrm{CC} 2, \mathrm{CC} 3$, CC8, CC87, CC121, CC155, CC199, and $\mathrm{CC} 224)$. Among these, $\mathrm{CC} 2, \mathrm{CC} 3, \mathrm{CC} 8$, and $\mathrm{CC} 155$ were represented by two or three STs while the other five $\mathrm{CCs}$ were represented by only one ST. Of note, 34/47 sequences belonged to hypervirulent $\mathrm{CC} 1, \mathrm{CC} 2$, and $\mathrm{CC} 3$ (Figure 1). In relation to the time frame of sampling, ST2 was isolated throughout the years (except in winter 2013, autumn 2015, and winter 2015), with the peak being in summer $(9 / 17)$. Of note, ST2 was repeatedly collected from sliced meat products of the manufacturer A during the period 2014-2015 (summer 2014, $\mathrm{n}=2$; autumn 2014, $\mathrm{n}=1$; and summer 2015, $\mathrm{n}=1$ ). For ST3, this genotype was intermittently isolated during the study period. Most ST3 isolates were detected in spring (7/12), followed by autumn (3/12). Similar to ST2, ST3 was repeatedly isolated from sliced meat products of the manufacturer $B$ (autumn 2013, $\mathrm{n}=3$; and spring 2014, $\mathrm{n}=4$ ) and the manufacturer $\mathrm{C}$ (spring 2015, $\mathrm{n}=3$; and summer $2015 \mathrm{n}=1$ ). These results suggest that ST2 and ST3 could persist in sliced meat processing plants during a relatively long time period.

\section{Discussion}

Listeria monocytogenes contamination in RTE foods is a well-documented foodsafety problem. Despite strict international regulations and control, outbreaks and precautionary food recall events associated with $L$. monocytogenes contamination are still frequently notified (CDC, 2019). The persistence of L. monocytogenes in RTE foods could be explained by its ubiquitousness in diverse environments, its ability to form biofilms and grow at refrigerated temperatures (Kocot and Olszewska, 2017; Walker et al., 1990). Indeed, $L$. monocytogenes has been isolated from soil, water, feed, and especially food processing facilities (Alonso et al., 2014; Berrang et al. 2010; Linke et al., 2014). Furthermore, biofilm formation allows the bacterium to resist extreme conditions and persist for long periods on both nutritive and non-nutritive surfaces, especially in areas that are difficult to sanitize (Alonso et al., 2014; Kocot and Olszewska, 2017). Consequently, end products could be crosscontaminated through handling processes. Management of hazards associated with $L$. monocytogenes contamination in RTE foods requires extensive knowledge of the bacterium's occurrence in the products and its temporal fluctuation, in order to set up proper monitoring systems and control measures. Additionally, understanding the molecular characteristics of $L$. monocytogenes isolates is of paramount importance to identify the contamination source and elaborate prevention strategies (Wu et al., 2016).

In this study, the occurrence and molecular epidemiology of $L$. monocytogenes were investigated in RTE sausages and sliced meats commercialized in local stores and supermarkets in Hanoi, Vietnam during the period of 2013-2015. The occurrence of $L$. monocytogenes ranged from 8.2 to $20.0 \%$ in sausages and 26.8 to $35.4 \%$ in sliced meats during the study period. According to Vietnam Ministry of Health's Decision No 46/2007/QD-BYT on Promulgation Regulation of Maximum Level of Biological and Chemical Pollution in Food, Vietnam has a zero tolerance regarding L. monocytogenes in RTE meats. Therefore, positive samples identified in this study are not compliant to the Vietnamese

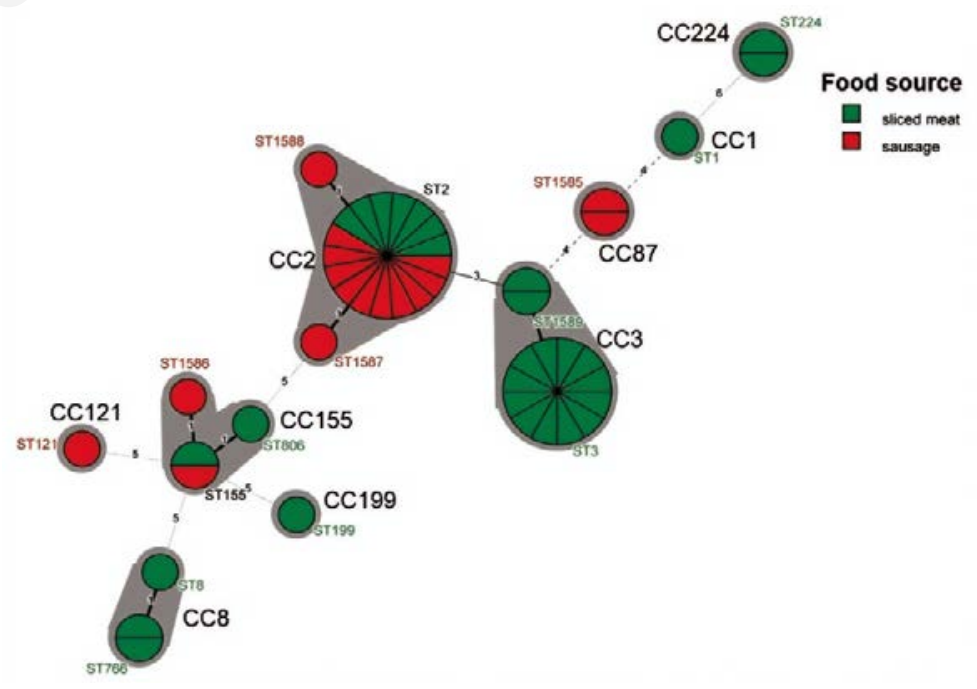

Figure 1. Minimum spanning tree showing genetic relatedness between 47 Listeria monocytogenes isolated from ready-to-eat meats in Hanoi, Vietnam. Each circle represents one sequence type (ST) and their sizes are proportional to the number of strains. The circles were subdivided into one pie slice per isolate. Links between circles represent the number of allelic mismatches between STs, as indicated. Gray zones around STs represent clonal complex (CC), as indicated. laws. Higher occurrences of $L$. monocytogenes in RTE sliced meats could be due to the fact that the manufacturing process of this product category in Vietnam is less automated than that of RTE sausages. Specifically, slicing and packaging steps of sliced meat products are performed manually in most food manufacturing plants in Vietnam. Therefore, cross-contamination of sliced meat products with persistent strains could occur during these steps. The presence of ST2 or ST3 in multiple sliced meat samples from the same manufacturers in this study strongly supports this speculation.

According to previous reports, the occurrence of $L$. monocytogenes in RTE meats varies between countries and regions. In Americas, estimates of $L$. monocytogenes occurrence in deli meats (sliced meat) and sausages were reported at approximately 0.2 $\%$ for the United States (Luchansky et al., 2017), whereas in Brazil, L. monocytogenes contamination in sausages could be as high as $39.8 \%$ (Asturiano Ristori et al., 2014). Similarly, highly divergent values were reported for European countries (EFSA, 2018). Occurrence of L. monocytogenes in heat-treated/cooked meat products (or sausages) in Sweden, United Kingdom, Poland, and Italy were found to be between 1.20 and 2.38\% (Iannetti et al., 2016; Kurpas et al., 2018); whereas slightly higher values were found for Austria, Spain, and Turkey, between 4.5 and $6.4 \%$ (Kurpas et al., 2018). However, the occurrence of $L$. monocytogenes in RTE sausages could be as high as $54 \%$ in Slovakia (Kačániová et al., 2015). For Asian countries, a recent study in China suggested that L. monocytogenes 
occurred in $13.5 \%$ of RTE pork (Wang et al., 2018). In Malaysia, approximately 13.2 $\%$ of RTE chicken and $6.7 \%$ of RTE beef products were contaminated with $L$. monocytogenes (Jamali et al., 2013). Significantly lower contamination rates were found in RTE meats in Thailand and Japan, at $3.3 \%$ in ham salad and $0.8 \%$ in heattreated RTE meats respectively (Shimojima et al., 2016; Stonsaovapak and Boonyaratanakornkit, 2010). In Vietnam, Thuc et al. (2008) revealed that the occurrence of L. monocytogenes in RTE sausages in Hanoi was $21.7 \%$, which is comparable to our results. Overall, the occurrence of L. monocytogenes in RTE meats in Hanoi, Vietnam, could be considered high among Asian countries.

The seasonal occurrence of $L$. monocytogenes in RTE sausage and sliced meat was found to be the highest in summer, which is in line with studies by Rivoal et al. (2010) and Sauders et al. (2012). Nonetheless, data on seasonal variation of $L$. monocytogenes from different investigators are not in total agreement, with the peak of occurrence being in spring (Dalzini et al., 2016), autumn (Elmali et al., 2015), winter (Wang et al., 2018) or no clear pattern of seasonality at all (Mohammed et al., 2010). The increase of L. monocytogenes occurrence during summer months could be due to higher ambient temperature that supports L. monocytogenes proliferation in raw materials. As a result, heat treatment procedures were not able to completely eradicate its contamination in the final products. Furthermore, higher ambient temperature could also accelerate the growth of the remaining bacteria during storage. Indeed, increases in growth rate were observed in studies by Uhlich et al. (2006) and Szczawiński et al. (2017) when different strains of $L$. monocytogenes were inoculated into food samples and kept at higher temperatures. Nevertheless, further studies are required to confirm these speculations.

In our study, the predominant clonal complexes identified were CC2 and CC3, which have been shown to be among the most globally prevalent isolates (Zhang et al., 2019). Additionally, these clonal complexes are hypervirulent and have been reported to cause food outbreaks (Maury et al., 2016). Clonal complex 2 was responsible for outbreaks in USA (pasteurized milk, 1983), United Kingdom and Ireland (pâté, 1987-1988), and Italy (corn and tuna salad, 1997) (Aureli et al., 2000; Cantinelli et al., 2013), whereas CC3 is prevalent in cooked products and includes a strain that caused 1994 Illinois chocolate milk outbreak (Cantinelli et al., 2013; Wang et al., 2018). Notably, hypervirulent CC2 and CC3 harbor three out of five novel STs identified in this study. Another hypervirulent clone (CC1) (Maury et al., 2016) was also detected, although, only in one sample. On the other hand, CC9 or CC121, which were reported in several foods or processing plants (Martin et al., 2014; Maury et al., 2016), were not common in Vietnam, as only one sausage sample was found to be contaminated with L. monocytogenes CC121. Altogether, these results revealed the pervasiveness of hypervirulent strains in RTE meats in Vietnam. This represents an increased risk to vulnerable populations, such as the elderly or pregnant women. Strikingly, in this study, ST2 and ST3 were isolated multiple times from sliced meat products of the same manufacturers during a relatively long time period. Previous studies have evidenced that ST2 and ST3 could persist in food processing facilities despite regular sanitization (Chen et al., 2019; Martin et al., 2014; Oxaran et al., 2017; Véghová et al., 2017). Therefore, the high occurrence of these strains in RTE meats in Vietnam is likely related to their persistence in food processing plants.

\section{Conclusions}

In conclusion, this is the first study to report the occurrence and molecular characteristics of L. monocytogenes in RTE meats in Vietnam. These data indicate the necessity to establish a monitoring system and control measures for L. monocytogenes at both production and retail levels in Vietnam.

\section{References}

Alonso AN, Perry KJ, Regeimbal JM, Regan PM, Higgins DE, 2014. Identification of Listeria monocytogenes Determinants Required for Biofilm Formation. PLOS ONE 9:e113696. doi:10.1371/journal.pone.0113696.

Asturiano Ristori C, Estela Gravato Rowlands R, Geraldes Martins C, Luisa Barbosa M, Yoshida JTU, Franco B, 2014. Prevalence and Populations of Listeria monocytogenes in Meat Products Retailed in Sao Paulo, Brazil. Foodborne Pathog Dis, 11. doi:10.1089/fpd.2014.1809.

Aureli P, Fiorucci GC, Caroli D, Marchiaro G, Novara O, Leone L, Salmaso S, 2000. An outbreak of febrile gastroenteritis associated with corn contaminated by Listeria monocytogenes. N Engl J Med 342:1236-41. doi:10.1056/nejm200004273421702.

Berrang ME, Frank JF, Meinersmann RJ, 2010. Listeria monocytogenes biofilm formation on silver ion impregnated cutting boards. Food Protection Trends 30:168-171.

Cantinelli T, Chenal-Francisque V, Diancourt L, Frezal L, Leclercq A, Wirth T, Lecuit M, Brysse S. 2013. "Epidemic clones" of Listeria monocytogenes are widespread and ancient clonal groups. J Clin Microbiol 51:3770-9. doi: $10.1128 / \mathrm{jcm} .01874-13$.

Center for Disease Control and Prevention, CDC (2019). Listeria Outbreaks. Available from https://www.cdc.gov/listeria/outbreaks/i ndex.html

Chen M, Cheng J, Zhang J, Chen Y, Zeng H, Xue L, Lei T, Pang R, Wu S, Wu H, Zhang S, Wei X, Zhang Y, Ding Y, Wu $\mathrm{Q}, 2019$. Isolation, Potential Virulence, and Population Diversity of Listeria monocytogenes From Meat and Meat Products in China. Front Microbiol 10:946. doi:10.3389/fmicb.2019.00946.

Dalzini E, Bernini V, Bertasi B, Daminelli P, Losio MN, Varisco G, 2016. Survey of prevalence and seasonal variability of Listeria monocytogenes in raw cow milk from Northern Italy. Food Control 60:466-70.

doi:https://doi.org/10.1016/j.foodcont.20 15.08.019.

Desai AN, Anyoha A, Madoff LC, Lassmann B, 2019. Changing epidemiology of Listeria monocytogenes outbreaks, sporadic cases, and recalls globally: A review of ProMED reports from 1996 to 2018. Int $\mathrm{J}$ Infect Dis $84: 48-53$. doi:10.1016/j.ijid.2019.04.021.

Di Bonaventura G, Piccolomini R, Paludi D, D'Orio V, Vergara A, Conter M, Ianieri A, 2008. Influence of temperature on biofilm formation by Listeria monocytogenes on various food-contact surfaces: relationship with motility and cell surface hydrophobicity. J Appl Microbiol 104:1552-61. doi:10.1111/j.1365-2672.2007.03688.x.

Di Pinto A, Novello L, Montemurro F, Bonerba E, Tantillo G, 2010. Occurrence of Listeria monocytogenes in ready-toeat foods from supermarkets in Southern Italy. New Microbiol 33:249-52.

ECDC-EFSA, 2019. Multi-country outbreak of Listeria monocytogenes sequence type 6 infections linked to ready-toeatmeat products - 25 November 2019 . EFSA Supporting Publications, 16:1745E. doi:10.2903/sp.efsa.2019.EN-1745.

EFSA, 2018. Listeria monocytogenes contamination of ready-to-eat foods and 
the risk for human health in the EU. EFSA Journal, 16:e05134. doi:10.2903/j.efsa.2018.5134.

Elmali M, Can HYI, Yaman H, 2015. Prevalence of Listeria monocytogenes in poultry meat. J Food Sci Technol 35:672-5.

Furrer B, Candrian U, Hoefelein C, Luethy J, 1991. Detection and identification of Listeria monocytogenes in cooked sausage products and in milk by in vitro amplification of haemolysin gene fragments. J Appl Bacteriol 70:372-9. doi:10.1111/j.13652672.1991.tb02951.x.

Jamali H, Chai LC, Thong KL, 2013. Detection and isolation of Listeria spp. and Listeria monocytogenes in ready-toeat foods with various selective culture media. Food Control 32:19-24. doi:https://doi.org/10.1016/j.foodcont.20 12.11.033.

Iannetti L, Acciari VA, Antoci S, Addante N, Bardasi L, Bilei S, Calistri P, Cito F, Cogoni P, D'Aurelio R, Decastelli L, Iannetti S, Iannitto $G$, Marino AMF, Muliari R, Neri D, Perilli M, Pompilio F, Prencipe VA, Proroga Y, Santarelli GA, Sericola M, Torresi M, Migliorati G, 2016. Listeria monocytogenes in readyto-eat foods in Italy: Prevalence of contamination at retail and characterisation of strains from meat products and cheese. Food Control 68:55-61.

doi:https://doi.org/10.1016/j.foodcont.20 16.03.036

Kačániová M, Kluz M, Petrová J, Mellen M, Kunová S, Haščík $P$, Lupašovský 1 , 2015. Incidence of Listeria monocytogenes in meat product samples by real time PCR. Mod Chem Appl 3:15.

Kocot AM, Olszewska MA, 2017. Biofilm formation and microscopic analysis of biofilms formed by Listeria monocytogenes in a food processing context. LWT 84:47-57. doi:https://doi. org/10.1016/j.lwt.2017.05.042.

Kurpas M, Wieczorek K, Osek J, 2018. Ready-to-eat Meat Products As a Source of Listeria Monocytogenes. J Vet Res 62:49-55. doi:10.1515/jvetres-20180007 .

Linke K, Rückerl I, Brugger K, Karpiskova R, Walland J, Muri-Klinger S, Tichy A, Wagner M, Stessl B, (2014). Reservoirs of listeria species in three environmental ecosystems. Appl Environm Microbiol 80:5583-92. doi:10.1128/AEM.0101814.

Luchansky JB, Chen Y, Porto-Fett ACS, Pouillot R, Shoyer BA, JohnsonDeRycke R, Eblen DR, Hoelzer K,
Shawn Jr WK, van Doren JM, Catlin M, Lee J, Tikekal R, Gallagher D, Lindsay JA, Listeria Market Basket MultiInstitutional Team, Dennis S, 2017. Survey for Listeria monocytogenes in and on Ready-to-Eat Foods from Retail Establishments in the United States (2010 through 2013): Assessing Potential Changes of Pathogen Prevalence and Levels in a Decade. J Food Prot 80:903-21. doi:10.4315/0362028x.Jfp-16-420.

Martin B, Perich A, Gomez D, Yanguela J, Rodriguez A, Garriga M, Aymerich T, 2014. Diversity and distribution of Listeria monocytogenes in meat processing plants. Food Microbiol $44 \quad: 119-27 . \quad$ doi:10.1016/j.fm. 2014.05.014.

Maury MM, Tsai YH, Charlier C, Touchon M, Chenal-Francisque V, Leclercq A, Crisculo A, Gaultier C, Roussel S, Brisabois A, Disson O, Roca Brisse S, Lecuit M, 2016. Uncovering Listeria monocytogenes hypervirulence by harnessing its biodiversity. Nature genetics, 48, 308-313. doi:10.1038 /ng.3501.

Mohammed HO, Atwill E, Dunbar L, Ward T, McDonough P, Gonzalez R, Stipetic $\mathrm{K}$, 2010. The risk of Listeria monocytogenes infection in beef cattle operations. J Appl Microbiol 108:34956.

doi:10.1111/j.1365-2672.2009.04446.x.

Ngo CT, Patin A, Truong TG, Pham TN, Tran TH, Le Bas C, 2008. Occurrence of listeria monocytogenes in retail pork meat in Vietnam. Paper presented at the Proceedings of the PRISE Scientific Committee, Hanoi, Viet Nam.

Oxaran V, Lee SHI, Chaul LT, Corassin CH, Barancelli GV, Alves VF, De Oliveira CAF, Gram L, De Martinis ECP, 2017. Listeria monocytogenes incidence changes and diversity in some Brazilian dairy industries and retail products. Food Microbiol, 68:16-23. doi:https://doi. org/10.1016/j.fm.2017.06.012.

Pohlert T, 2015. trend: Non-Parametric Trend Tests and Change-Point Detection, R package version 0.0.1.

Ragon M, Wirth T, Hollandt F, Lavenir R, Lecuit M, Le Monnier A, Brisse S, 2008. A New Perspective on Listeria monocytogenes Evolution. PLOS Pathogens 4 :e1000146. doi:10.1371/ journal.ppat.1000146

Rivoal K, Queguiner S, Boscher E, Bougeard S, Ermel G, Salvat G, Federighi M, Jugiau F, Protais J, 2010. Detection of Listeria monocytogenes in raw and pasteurized liquid whole eggs and characterization by PFGE. Int $\mathrm{J}$
Food Microbiol 138:56-62. doi:10.1016/j.ijfoodmicro.2010.01.013

Rogalla D, Bomar P, 2019. Listeria Monocytogenes. StatPearls. Available from: https://www.ncbi.nlm.nih.gov/ books/NBK534838/

Sauders BD, Overdevest J, Fortes E, Windham K, Schukken Y, Lembo A, Wiedmann M, 2012. Diversity of Listeria species in urban and natural environments. Appl Environ Microbiol 78:4420-33. doi:10.1128/aem.00282-12.

Schlech, W. F., 3rd. 2000. Foodborne listeriosis. Clin Infect Dis, 31 :770-5. doi: $10.1086 / 314008$.

Shimojima Y, Ida M, Nakama A, Nishino Y, Fukui R, Kuroda S, Hirai H, Kai A, Sadamasu K, 2016. Prevalence and contamination levels of listeria monocytogenes in ready-to-eat foods in Tokyo, Japan. Journal Vet Med Sci 78:1183-7. doi:10.1292/jvms.15-0708.

Stonsaovapak S, Boonyaratanakornkit M, 2010. Prevalence and antimicrobial resistance of listeria species in food products in Bangkok, Thailand. J Food Safety 30:154-161. doi:10.1111/j.17454565.2009.00197.x

Szczawiński, J., Ewa Szczawińska, M., Łobacz, A., Tracz, M., \& JackowskaTracz, A, 2017. Modelling the Growth Rate of Listeria Monocytogenes in Cooked Ham Stored at Different Temperatures. Journal Vet Res, 61:4551. doi:10.1515/jvetres-2017-0006

Tabit F, 2018. Contamination, Prevention and Control of Listeria monocytogenes in Food Processing and Food Service Environments. In: Nyila M.A. (eds.) Listeria Monocytogenes. IntechOpen.

Thuc NM, Hung TM, Le TT, Anh TK, 2008. Primary investigation of Listeria monocytogenes infection in foods in Hanoi market using polymerase chain reaction. Vietnam J Sci Technol 46:6777.

Uhlich GA, Luchansky JB, Tamplin ML, Molina-Corral FJ, Anandan S, Porto-Fett ACS, 2006. Effect of storage temperature on the growth of Listeria Monocytogenes on Queso Blanco slices. J Food Safety 26:202-14. doi:10.1111/j.1745-4565.2006.00043.x.

Véghová A, Minarovičová J, Koreňová J, Drahovská H, Kaclíková E, 2017. Prevalence and tracing of persistent Listeria monocytogenes strains in meat processing facility production chain. J Food Safety 37:e12315. doi:10.1111/ jfs. 12315.

Walker SJ, Archer P, Banks JG, 1990. Growth of Listeria monocytogenes at refrigeration temperatures. J Appl Bacteriol 68:157-62. doi:10.1111/j.1365- 
2672.1990.tb02561.x

Wang H, Luo L, Zhang Z, Deng J, Wang Y, Miao Y, Zhang L, Chen X, Liu X, Sun S, Xiao B, Li Q, Ye C, 2018. Prevalence and molecular characteristics of Listeria monocytogenes in cooked products and its comparison with isolates from listeriosis cases. Front Med 12:104-12. doi:10.1007/s11684-017-0593-9

WHO, World Health Organization, 2019. Listeriosis- Spain. Retrieved from https://www.who.int/csr/don/16september-2019-listeriosis-spain/en/ Wu S, Wu Q, Zhang J, Chen M, Guo W, 2016. Analysis of Multilocus Sequence Typing and Virulence Characterization of Listeria monocytogenes Isolates from Chinese Retail Ready-to-Eat Food. Front Microbiol $7: 168$ doi:10.3389/fmicb.2016.00168

Xuan Binh D, Minh N, Thi Nguyet D, 2017. Prevalence of Listeria monocytogenes,
E. coli, Salmonella Spp. and Staphylococcus aureus Bacteria Contamination on Meat at Public Market in the North of Vietnam (Vol. 5).

Zhang X, Niu Y, Liu Y, Lu Z, Wang D, Cui X, Chen Q, Ma X, 2019. Isolation and Characterization of Clinical Listeria monocytogenes in Beijing, China, 2014 2016. Front Microbiol 10:981. doi:10.3389/fmicb.2019.00981 